\title{
Comparison of Serological Tests in Cattle and Ovine Brucellosis; An Abattoir Study in Algeria
}

\author{
Maamar Khames $^{1 *}$, Amaia Zúñiga-Ripa ${ }^{2}$, Sagrario Pérez Gómez ${ }^{3}$, Mustapha Oumouna $^{1}$ and Ignacio Moriyón ${ }^{2}$ \\ ${ }^{I}$ Department of Biology, University of Medea, Medea, Algeria \\ ${ }^{2}$ Institute of Tropical Health and Department of Microbiology and Parasitology, Faculty of Medicine, University of Navarra, Pamplona, Spain \\ ${ }^{3}$ Laboratorio de Calidad Agroalimentaria, Navarra, Spain \\ *Corresponding author`s Email: drkhames86@gmail.com; (DorCiD: 0000-0001-6820-0496
}

\begin{abstract}
Despite the paucity of data, brucellosis is considered as a major problem in Algeria. The aim of present study was to assess the presence of bovine and ovine brucellosis in the areas close to the capital city (Algiers) where its vaccination is not implemented. A total of 402 cattle and 203 ovine sera were collected from two slaughterhouses, and examined by the Rose Bengal Test (RBT). Positive samples were then tested by Complement Fixation Test (CFT) and Hypertonic Double Gel Diffusion (DDG) with a smooth lipopolysaccharide, and the extract of native hapten was also tested by Indirect Enzyme Linked Immuno Sorbent Assay (iELISAs) with smooth lipopolysaccharide and polyclonal or protein $\mathrm{G}$ conjugates. Twenty-four bovine sera (5.97\%) were RBT positive. Of these, 23 were positive in CFT, DDG, and 16 samples were also positive in iELISA when the assay was adjusted to $100 \%$ specificity. Only two ovine sera were RBT positive; one was CFT and DDG positive, and the other one had a CFT-titer of $1 / 4$, and was DDG negative. This preliminary study confirmed that bovine brucellosis is a major problem in Algeria, and indicated that some field studies are needed to determine the prevalence of Brucellosis in Algeria urgently. Similarly, other studies are necessary in areas with dominance of ovine breeding system. Further studies in the areas with a dominance of ovine breeding system are necessary. The results of this work showed that simple tests like RBT and DDG are not outperformed by CFT or iELISA for assessing the apparent prevalence of brucellosis in the absence of vaccination. Finally, isolation and typing of the involved Brucella species are also necessary in order to have a complete epidemiological picture of brucellosis in Algeria.
\end{abstract}

Key words:Abattoirs, Algeria, Brucellosis, Cattle, Serology, Sheep, Prevalence

\section{INTRODUCTION}

Bacteria of the genus Brucella which causes brucellosis is a highly contagious zoonosis affecting primarily domestic livestock and a variety of wild-life species. Brucellosis in animals is characterized by a reproductive failure, and the human form of this disease is a grave and debilitating condition requiring prolonged and costly antibiotic treatments. Thus, this disease presents a serious threat to the animal industry and public health (McDermott et al., 2013). Brucellosis is considered as one of the most widespread zoonosis in the world (Hull and Schumaker, 2018) and it has a great impact on emerging economies and resources of poor countries (Grace et al., 2012). Although it has been eradicated in ruminants in most European countries, the USA, Canada, Australia and a few other countries, brucellosis is still a endemic disease in many parts of the world, especially in North and East Africa, the Middle East, South and Central Asia and Central and South America (Corbel, 2006). Moreover, intensification of breeding caused by raising food demand increased the risk of spread of this and other zoonosis (Jones et al., 2013).

Humans contract the disease from animals or their products, but they are not considered as a source of contagion. Thus, under most circumstances, human brucellosis is the best indicator of the existence of the disease in animals. Regarding, the high number of cases for human brucellosis reported in Algeria is indicative of the important impact of this zoonosis in the country, 819 human cases were recorded in first four months of 2016 (Robert, 2016). The intervention against brucellosis includes implementation of dairy food sanitation, specific measures to protect risk groups (farmers, abattoir workers and veterinarians), and control and eradication of the disease in livestock. In Algeria, despite the control program initiated in 1970 and strengthened in 1995 which was based principally on a test-and-slaughter strategy, bovine brucellosis is a serious problem in dairy herds in all likelihood as suggested by the consistent presence of clinical symptoms compared with the disease and occasional serological testing. About 30 years ago, Benelmouffok et al. (1984) summarized the previous evidence indicating high (up to 25\%) apparent seroprevalence as determined by the Standard Serum Agglutination Test (SAT). More recently, apparent herd seroprevalence of $26.3 \%$ using Rose Bengal Test (RBT) and $15.7 \%$ by complement fixation test (CFT) were reported for cattle in the Western area of Algeria (Tiaret) 
(Aggad and Boukraa, 2006). Although these reports suggest a high prevalence of bovine brucellosis, the paucity of data and their long-time span clearly indicated the need for additional studies. Similarly, there is a paucity of works on brucellosis in small ruminants (Hamdi-Chérif et al., 1999; Meskoud-taibi and Benzadi, 2009). However, while cattle are usually infected by B. abortus, sheep and goats are infected by B. melitensis, the Brucella species are considered to be more infectious for human (O'Callaghan, 2020). Accordingly, a first goal of the research described here was to obtain additional data on the status of brucellosis in Algeria. To this end, a serological study was carried out on two slaughterhouses that process animals coming from different areas of the country.

Because of the absence of pathognomonic symptoms, the diagnosis of brucellosis requires laboratory tests. Bacteriological culture is cumbersome and dangerous, but serological tests are routinely used. However, there is a bewildering list of serological tests (Ducrotoy et al., 2016), and most new developments are focused on tests suitable for surveillance of large numbers of animals in Brucella-free areas that require conditions not met in resource-limited settings (McGiven, 2013; Ducrotoy et al., 2015). Thus, a second aim of the present work was to compare apparent prevalence figures obtained with simple RBT, more sophisticated and highly-sensitive tests like indirect ELISA (iELISA) with tests of higher specificity that also differ in the degree of sophistication (CFT and double gel diffusion (DDG) with smooth-lipopolysaccharide (S-LPS) and native hapten polysaccharide (NH).

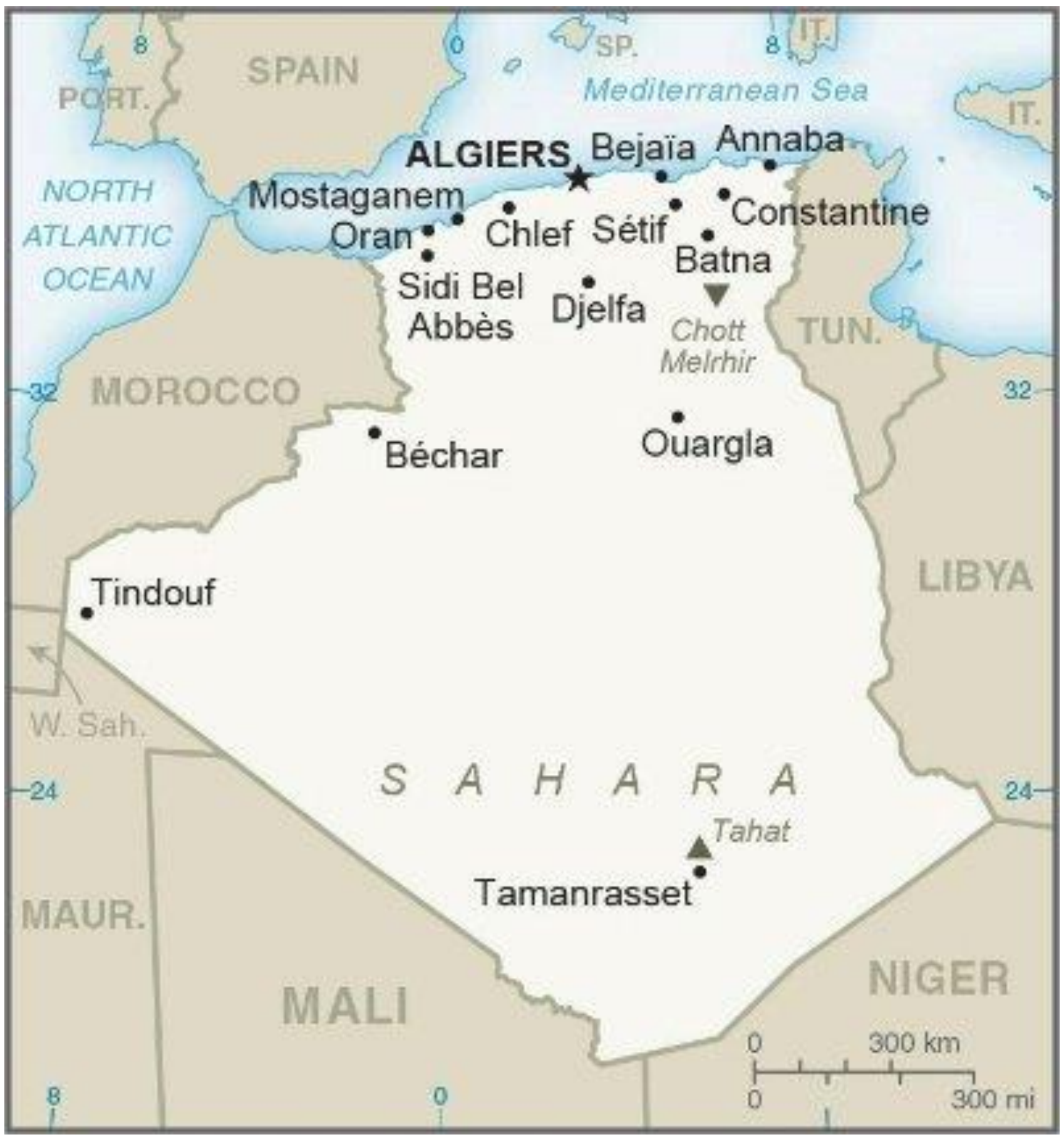

Figure 1A.General map of Algeria (http://www.state.gov/p/nea/ci/ag/) 


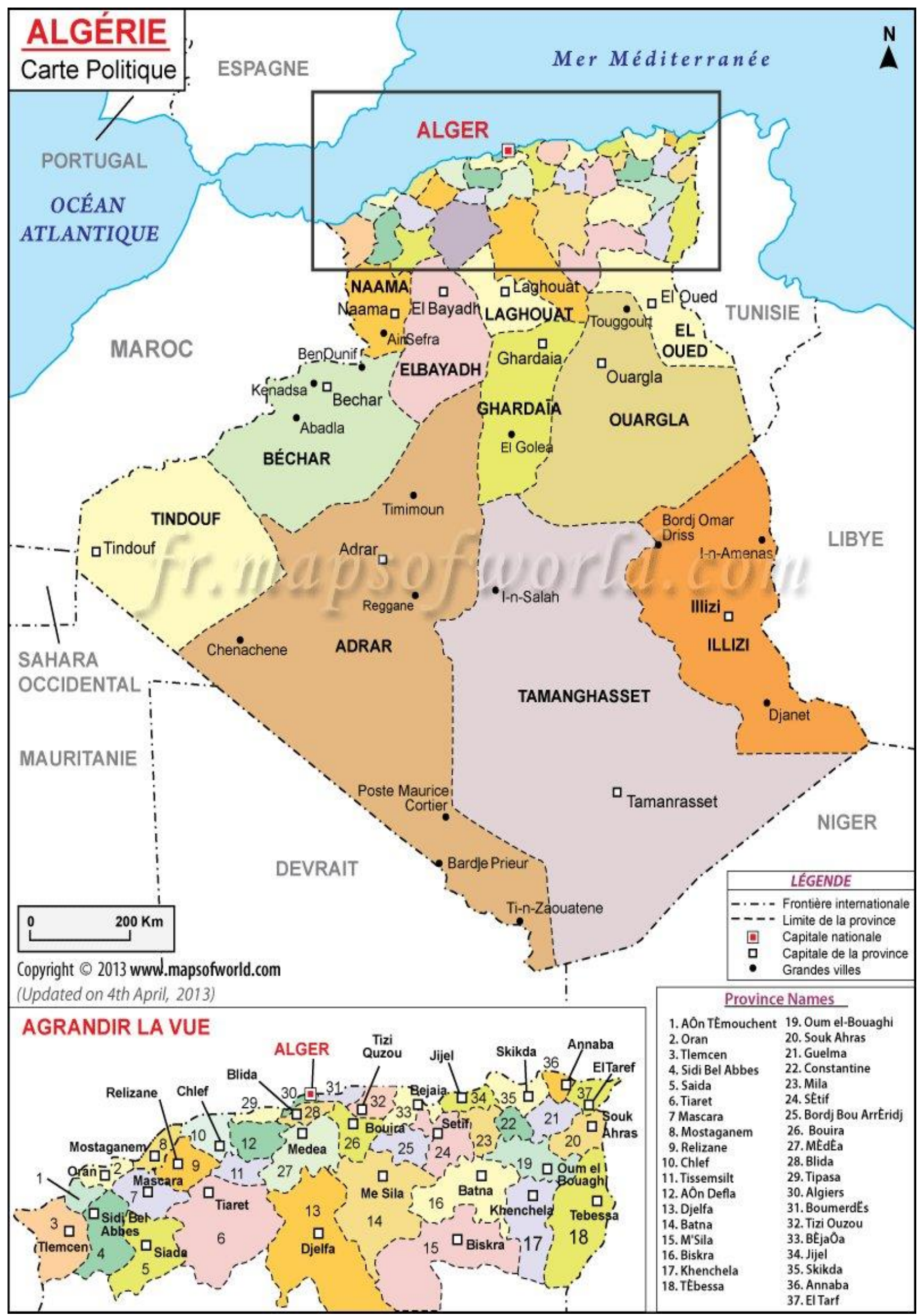

Figure 1B.The Wilayates close to Algiers (http://www.algerieprofonde.net/algerie/cartes-dalgerie/). The caption shows the total number of cattle tested from each place and the prevalence percent:Ain-Defla, n: $74(0.00 \%)$; Alger (Algiers), n: 86 (1.16\%); Blida, n: 58 (13.80\%); Bouira, n: 151 (7.28\%); Boumerdes, n: 27 (7.40\%); Chlef and Relizane, n: 5 (20.00\%); Médéa, n: 1 (100.00\%). 


\section{MATERIALSAND METHODS}

\section{Ethical approval}

Samples were collected as per the standard sample collection procedure without any stress or harm to the animals, according to the rules of the Veterinary School of Algiers, Algeria.

\section{Study site, period and sample size}

The study was carried out in two slaughterhouses in Algiers, Algeria. Originally in the outskirts, the Rouiba slaughterhouse is now in the urban area. This slaughterhouse is working each day of the week, and animals from different areas are processed. So, it made it possible to trace the geographical origin of the cattle. El-Harrach slaughterhouse (about $2600 \mathrm{~m}^{2}$ ) is located in the urban area, and it was not possible to trace the origin of the animals due to the work's conditions there. For the Rouiba slaughterhouse, the study included the entire cattle population (402heads: 264females and138males) of every breed (local, cross-breed and montbeliarde) and age sacrificed from 26 February to 1 April 2012, and63 non-vaccinated sheep (19 females and 44 males) were sacrificed from1 to 28 February 2012; for ElHarrach slaughterhouse, 140 non-vaccinated sheep of different breeds like ouled djellal and el rembi, and different age categories (86 females and 54 males) were sacrificedfrom1 to 31 March 2012.

\section{Ante mortem inspection}

An inspection to determine the sex, age and identification status on both ears was performed, and three types of cattle were defined; imported (Montbeliarde cattle; foreign identification tag), local (small, uniform colored dress - black or brown - no tag), Magpie black or red magpie crossbreed cattle (with or without tag (deleted or removed)).

\section{Sample collection}

Five milliliters of blood were collected from the jugular or the caudal vein with Vacutainer-type tubes, or directly at the moment of scarification, and all data (breed, age, sex and pregnancy) were recorded. The blood was let to clot at the room temperature, the sera were collected by centrifugation, 3000 tours per minute for 15 minutes, and finally stored at $-20^{\circ} \mathrm{C}$ until being analyzed.

\section{Serological tests}

All cattle's serum samples were analyzed by the RBT using the official Spanish antigen (kindly provided by Dr. J.M. Blasco, Centro de Investigación en Tecnologia Agraria, Gobierno de Aragón, Spain) according to the standard procedure (OIE, 2016). Briefly, after equilibrating the antigen suspension at the room temperature, an equal volume $(25 \mu 1)$ of antigen and serum were mixed on a white tile with a toothpick, and shaked by hands for 4 minutes. No matter the intensity, definite clumping/agglutination was considered as a positive reaction. Sheep's serum samples were analyzed by the modified RBT (mRBT) (Blasco et al., 1994;Diaz-Aparicio et al., 1994;OIE, 2016). A volume of 25 $\mu 1$ of antigen and $75 \mu 1$ of serum were used. In all cases, RBT-positive serum samples were then retested for CFT which was performed by the standard micro method technique (OIE, 2016)(a titer equal to 4 contained 20 international CFT units per ml). In addition, RBT-positive sera(or MRBT for sheep) were analyzed by the DGD immunoprecipitation test with a hot extract of B. melitensis $16 \mathrm{M}$ rich in native hapten $(\mathrm{NH})$ and Smooth lipopolysaccharides (S-LPS) in $10 \% \mathrm{NaCl}$ hypertonic gels (Diaz et al., 1981). Two antigen concentrations were used: 1 and 5mg/ml. Finally, an in-house iELISA with polyclonal and protein G conjugates and smooth B. abortus S-LPS was performed as described before (AlonsoUrmeneta et al., 1998). Plates included both a positive and a negative control, and the results were expressed as the optical density (\%OD) of the positive control. The iELISA and DDG antigens were supplied by the Brucellosis Laboratory, Institute of Tropical Health, University of Navarra. Complement fixation test (CFT) was performed at the laboratory for food quality, Government of Navarra, Navarra, Spain. The Laboratorio de Calidad Agroalimentaria, Gobierno de Navarra, Villaba, Navarra, Spain.

\section{Statistical analysis}

The results were analyzed using the Chi square test (SPSS, version 19) and P values $<0.05$ were considered significant. Confidence intervals were calculated according to Toma et al. (1996)

\section{RESULTS AND DISCUSSION}

\section{Cattle}

Twenty-four samples of bovine sera were positive by RBT (Apparent prevalence: 5.97\%, 95\% confidence interval, 5.95 - 5.99). Of these, 23 were positive by CFT, DDG (i.e. apparent prevalence: 5.72\% CI (5.7-5.74in all cases), and 16 samples by iELISA (i.e. apparent prevalence: $3.98 \%$ CI (3.96-4)). By CFT, 18 samples had titers equal to or higher 
than $1 / 256 ; 2,1 / 128 ; 1,1 / 64 ; 1,1 / 16$ and 1, 1/4. By DDG with the antigen at 1mg/ml, 21 serum samples developed both the LPS and NH precipitin lines, one only with the S-LPS precipitin line, one only with the NH precipitin line, and one was negative. The serum that developed only the S-LPS precipitin line which reacted weakly in RBT had a CFT titer equal to $1 / 4$, and was positive in iELISA. The serum that was negative by DDG was also negative in the iELISA, but positive in the RBT and the CFT. For the DDG, the results were not improved by increasing the antigen concentration to $5 \mathrm{mg} / \mathrm{ml}$.

It has been consistently observed that a positive result of immunoprecipitation tests with extracts rich in S-LPS and NH correlated with a positive CFT (i.e. $\geq 1: 4$ (20 international units) or higher, so that the former can be substituted for the latter in the classical diagnostics scheme that started with RBT screening. However, while CFT is technically demanding, the DDG with these extracts represented a much simpler and repeatable test (Diaz et al., 1979;Jones et al., 1980;Díaz et al., 1984;Diaz-Aparicio et al., 1993). Moreover, it has been observed that a positive result in the DDG test correlates with the shedding of Brucella which makes this test particularly useful in difficult epidemiological situations when identification of shedders becomes necessary to control brucellosis (Jones et al., 1980). The results presented here confirmed the previous investigations that demonstrated that a combination of RBT and DDG can be implemented without a loss of performance with respect to that obtained with more sophisticated CFT and iELISA (Diaz et al., 1979; Jones et al., 1980; Diaz et al., 1981; Diaz et al., 1983; Muñoz et al., 2005). It has been argued that the immunoprecipitation tests with S-LPS and NH are not sensitive enough to be useful in the diagnosis of brucellosis, and that they are outperformed by immunoenzymatic tests with diagnostic sensitivity and specificity adjusted according to the Youden or performance indexes (Nielsen, 2002). However, because brucellosis does not spread epizootically, early detection requiring $100 \%$ diagnostic sensitivity is not as critical as in highly transmissible epizootic diseases. Moreover, the diagnosis of brucellosis should be interpreted on a herd/flock rather than on an individual basis, and when the objective is the culling of positive animals in eradication contexts, it is repeated frequently over time which facilitates the detection of infected animals. Thus, 100 percent of DSe is not strictly necessary for brucellosis tests, and low DSp generates unnecessary culling with the ensuing conflicts with farmers, needless quarantines, and trade and policy problems (Ducrotoy et al., 2018). Quantitative tests such as iELISA are usually adjusted according to the Youden index which maximizes the DSe/DSp balance. Yet, as shown here, when the DSp was adjusted to $100 \%$, the DSe decreased with regard to the simpler RBT or DDG. As these last two tests are robust, and can be performed with relatively little equipment, they can be recommended for use in laboratories where manpower is not the limiting factor, and access to automatized systems is not available. In fact, these immunoprecipitation tests have been used extensively and successfully as confirmatory tests after a RBT screening in eradication campaigns in northern Spain (Asarta, 1989; Blasco et al., 2016). Indeed, a problem of DGD is the availability of the NH and S-LPS extract. Although there are simple extraction protocols (Díaz et al., 1984), the antigen is not presently commercially available.

In cattle, the close parallelism among the apparent prevalence figures obtained with the different tests is remarkable. Compared to the CFT or iELISA tests, it has been shown that the immunoprecipitation test with NH is only not affected by false positive reactions caused by bacteria cross-reacting with Brucella at the LPS level (Muñoz et al., 2005). Taken together, this high specificity and the absence of S19 vaccination in the origin areas of the tested animals support the conclusion that the apparent prevalence figures obtained with this test actually represent real infections by either B. abortus or B. melitensis. The latter species was known to be a cause of infections in cattle in areas where they are raised and kept with the small ruminants (Verger et al., 1989), and as serological tests cannot differentiate infections by those two species (Ducrotoy et al., 2016), bacteriological studies are necessary for a full understanding of the epidemiology of brucellosis in Algeria. Cattle identification system allowed us to trace back their origin, thereby, all livestock markets were represented at the Rouiba abattoir (i.e. Bouira (Center), Médéa (Center), Blida (Center), Ain ElDefla (West), Algiers (Center), Chlef and Relizane (West), Boumerdès (Center); supplemental figure S1), only one (Ain El-Defla) did not yield any seropositive animal. This illustrated that cattle brucellosis is widespread in the country.

Concerning other epidemiological factors, table 1 summarizes the results broken down according to sex, age, breed and other characteristics recorded. As can be seen, the proportion of seropositive individuals was much higher in females than in males. The literature contained contradictory reports on the influence of sex as a risk factor in cattle brucellosis. Whereas some authors reported that males are at a higher risk (Boukary et al., 2013), others found opposite results (Kebede et al., 2008; Mohammed et al., 2011; Rahman et al., 2011; Olabode et al., 2012). However, it is known that the management determined the rates of infection in males. Artificial insemination is extended in Algeria, and in the present study, all138 males were slaughtered for meat when they were less than two years old, instead of using them as breeding males which prevented them from getting infected from the females. Among the females, only one was less than 2 years old. This bias in the sample reflected the management of the animals in the dairies of Algeria where old females are removed from the farms when the productivity decreases. Similarly, most of the tested animals belonged to the crossbreed category, and this also reflected the preference of the farmers for these animals because of the better milk yields and comparative lower market prices. However, the data showed that there were no statistically significant differences in apparent seroprevalence among this and the other two groups identified in the study. 
Out of 46 identified cattle samples, $10(21.73 \%)$ were positive. Ten out of the $305(3.27 \%)$ non-identified cattle and 4out of the 51(7.84\%) cattle samples that presented are moved ear-tag were found positive (Table 1). Statistically, there was a significant association $(\mathrm{p}<0.05)$ between the apparent prevalence and the identification status. Supposedly, identified animals were screened regularly for brucellosis by Veterinarian Services, and those found positive should be sacrificed. However, owners most often postpone culling, and send the animals to the market according to their own needs. Thus, the sub-sample of identified animals was biased and should contain a higher proportion of seropositive animals, as the results confirmed. The same explanation was likely to apply to those animals from which the ear tag was removed before being sold. Also, in present study, a high proportion (305 out of 402) of cattle was unidentified. These observations were not anecdotal because they reflected the difficulties existing in controlling the disease in Algeria. Indeed, since a serological follow up is strictly necessary, proper animal identification is essential to apply control measures based on the individual vaccination (Blasco and Molina-Flores, 2011; Blasco et al., 2016).

Three out of the $21(14.28 \%)$ pregnant females and 20 out of the $235(8.51 \%)$ non-pregnant females were found positive (Table 1). Statistically, there was a significant association $(\mathrm{p}<0.05)$ between apparent prevalence and the pregnancy. Presence of pregnant females in the slaughterhouse could be explained by misdiagnosis of the pregnancy status by the veterinarians who delivered the slaughter certificates. However, of these three animals, one belonged to the identified group and another had the removed ear tag. Thus, an alternative explanation was an owner decision based on an awareness of the disease. The existence of infected pregnant animals was significant because these animals play a very important role in the transmission of the disease (Blasco et al., 2016).

Table 1. Results of brucellosis by serological tests in cattle according to sex, age, breed and identification status in Algeria

\begin{tabular}{llccccc}
\hline \multirow{2}{*}{ Items } & & \multicolumn{3}{c}{ Number of positive results (\%) in the indicated tests } \\
\cline { 3 - 7 } & & $\mathbf{N}^{\circ}$ of animals & RBT & CF & DDG-NH & iELISA \\
\hline \multirow{2}{*}{ Sex } & Female & 264 & $23(8.71 \%)$ & $22(8.33 \%)$ & $22(8.33 \%)$ & $16(6.06 \%)$ \\
& Male & 138 & $1(0.72 \%)$ & $1(0.72 \%)$ & $1(0.72 \%)$ & $0(0.00 \%)$ \\
\hline Age & $<2$ years & 1 & $0(0.00 \%)$ & $0(0.00 \%)$ & $0(0.00 \%)$ & $0(0.00 \%)$ \\
(females) & $>$ yyears & 263 & $23(8.74 \%)$ & $22(8.36 \%)$ & $22(8.36 \%)$ & $16(6.08 \%)$ \\
\hline \multirow{2}{*}{ Breed } & Local & 33 & $1(3.03 \%)$ & $1(3.03 \%)$ & $1(3.03 \%)$ & $1(3.03 \%)$ \\
& Cross-breed & 344 & $22(6.39 \%)$ & $21(6.10 \%)$ & $21(6.10 \%)$ & $14(4.07 \%)$ \\
& Montbeliarde & 25 & $1(4.00 \%)$ & $1(4.00 \%)$ & $1(4.00 \%)$ & $1(4.00 \%)$ \\
Identification & Yes & 46 & $10(21.73 \%)$ & $10(21.73 \%)$ & $10(21.73 \%)$ & $8(17.39 \%)$ \\
status & No & 305 & $10(3.27 \%)$ & $10(3.27 \%)$ & $10(3.27 \%)$ & $6(1.96 \%)$ \\
& Ear tag removed & 51 & $4(7.84 \%)$ & $3(5.88 \%)$ & $3(5.88 \%)$ & $2(3.92 \%)$ \\
\hline Pregnancy & Pregnant & 21 & $3(14.28 \%)$ & $2(9.52 \%)$ & $2(9.52 \%)$ & $2(9.52 \%)$ \\
(females) & Non-pregnant & 235 & $20(8.51 \%)$ & $20(8.51 \%)$ & $20(8.51 \%)$ & $14(5.95 \%)$ \\
\hline
\end{tabular}

$\mathrm{N}^{\circ}$ : number; RBT: Rose Bengal Test; CF: complement fixation; DDG-NH: double gel diffusion-native hapten; iELISA: indirect Enzyme Linked ImmunoSorbent Assay

\section{Sheep}

Concerning the ovine sera, two samples $(0.98 \%)$ were positive by mRBT. By CFT, one sample had a titer of $1 / 4$, and the other one had a titer of 1/16. This last serum was found positive by DDG-NH, but only with antigen at $1 \mathrm{mg} / \mathrm{ml}$. This was consistent with previous observations that the NH-S-LPS antigen concentration needed to be comparatively reduced for optimal sensitivity in immunoprecipitation with sera from small ruminants (Diaz-Aparicio et al., 1993).These two animals belonged to the larger sheep sample (El-Harrach abattoir).

The apparent seroprevalence found in sheep was lower than 3.08 \% reported by Hamdi-Chérif et al.(1999) in the east of Algeria (Setif and M'sila, 1999), or the 7.2\% found by the National Institute of Veterinary Medicine of Algiers in 2007 (Meskoud-taibi and Benzadi, 2009), and several circumstances could explain the differences. First, these two surveys which were conducted before the benefits of Rev 1 vaccination campaigns (started in the spring of 2006) could be detectable. It was worth noting that those few positive results cannot be the result of post-vaccinal antibodies. None of the sheep carried the green tag was used to label vaccinated animals in Algeria. An alternative explanation is that the tested sheep came from a few intensive farms surrounding Algiers where the animals which were kept for fattening, and then sold to the slaughterhouse which favored control. The two seropositive sexually mature rams introduced from an infected breeding area, but this practice did not seem a significant risk. In cattle, as in sheep, males play no relevant role in spreading the disease by direct sexual contact (Alton, 1990; Nielsen and Duncan, 1990), while artificial insemination can be a risk, which is not practiced in Algeria. However, the survey in sheep revealed deficiencies in the implementation of those measures (permanent tagging, movements of animals of unknown status) that are essential to carry out brucellosis control and eradication programs. Finally, since the present study was carried on ovine brucellosis 
in a slaughterhouse in the capital city Algiers, the results did not reflect the epidemiological situation in Algeria, and more studies in areas with dominance of ovine/caprine breeding are necessary to determine the origin of the human disease.

\section{CONCLUSIONS}

The results of this survey confirmed the importance of cattle brucellosis in Algeria, and that a combination of Rose Bengal test (RBT) and double gel diffusion in gel (DDG)RBT and DDG can be implemented instead of the more sophisticated like complement fixation test (CFT) and indirect Enzyme Linked Immuno Sorbent Assay (iELISA) to determine the apparent prevalence figures. As RBT and DDG are robust and technically simple, they should be useful in laboratories with basic equipment and where manpower is not limiting. Further studies including bacteriological methods, are urgent to clarify the epidemiology of brucellosis in Algeria. Finally, the study highlights a significant absence of proper implementation of general measures (identification and tagging, control of animal movements) that are necessary for successful brucellosis control.

\section{Acknowledgements}

We thank Alberto Delgado López for skillful technical assistance and the veterinarians of the slaughterhouses of Rouiba and El-Harrach for their help. The authors of this study would like to thank the Institute of Tropical health for hosting Maamar Khames to perform the serological tests and the School of Sciences and Technology of the University of Medea (Algeria) for funding MK stay in Spain.

\section{Competing interests}

The authors declare that they have no conflict of interest with respect to the research, authorship, and/or publications of this article. The authors declare that they have no competing interests.

\section{Author's contribution}

Maamar Khames, Amaia Zúñiga-Ripa and Ignacio Moriyon designed the experiment and laboratory analyses. Ignacio Moriyon and Mustapha Oumouna designed article writing, revision and approval. Maamar Khames, Ignacio Moriyon and Mustapha Oumouna designed tabulation of experimental data, manuscript writing, commenting and approval. Sagrario Pérez Gómez helped in field study, collected data, laboratory analyses, statistical analysis, manuscript writing. All authors have read and approved the final manuscript.

\section{REFERENCES}

Aggad H and Boukraa L (2006). Prevalence of bovine and human brucellosis in western Algeria: Comparison of screening tests. Eastern Mediterranean Health Journal, 12: 119-128. Available at: http://www.emro.who.int/emhj-volume-12-2006/volume-12-issue-1-2/prevalence-ofbovine-and-human-brucellosis-in-western-algeria-comparison-of-screening-tests.html

Alonso-Urmeneta B, Marín C, Aragón V, Blasco J M, Díaz R and Moriyón I (1998). Evaluation of lipopolysaccharides and polysaccharides of different epitopic structures in the indirect enzyme-linked immunosorbent assay for diagnosis of brucellosis in small ruminants and cattle. Clinical and Diagnostic Laboratory Immunology, 5: 749-754. Available at: https://www.ncbi.nlm.nih.gov/pmc/articles/PMC96196/

Alton GG (1990). Brucella melitensis, 1887 TO 1987. In: Animal Brucellosis, Available at: https://www.routledge.com/AnimalBrucellosis/Nielsen/p/book/9781315890586

Asarta A (1989). Erradicación de la brucelosis en Navarra. In: Microbiología, S.E. de (Ed.), XII Congreso Nacional de Microbiología, Sociedad Española de Microbiología. Gráficas San JUan, HUarte-Pamplona, Navarra, Spain, Pamplona, pp. 371-375. Available at: http://crinoidea.semicrobiologia.org/info/XIICongreso/

Benelmouffok A, Cherif A and Taril A (1984). Bovine brucellosis in Algeria. Results of serological detection from 1969 to 1976. Archive de l'Institut Pasteur d'Alger, 53: 120-126. Available at: https://europepmc.org/article/med/6436120

Blasco JM, Garin-Bastuji B, Marin CM, Gerbier G, Fanlo J, Jiménez de Bagués MP and Cau C (1994). Efficacy of different Rose Bengal and complement fixation antigens for the diagnosis of Brucella melitensis infection in sheep and goats. Veterinary Research, 134: 415-420. DOI: http://www.doi.org/10.1136/vr.134.16.415

Blasco JM and Molina-Flores B (2011). Control and Eradication of Brucella melitensis Infection in Sheep and Goats. Veterinary Clinics of North America: Food Animal Practice, 27: 95-104. DOI: http://www.doi.org/10.1016/j.cvfa.2010.10.003

Blasco JM, Moreno E and Moriyón I (2016). Brucellosis vaccines and vaccine candidates. In: Metwally, S., Viljoen, G.J., El Idrissi, A. (Eds.), Veterinary Vaccines for Developing Countries. FAO (Rome), Rome. DOI: http://www.doi.org/10.18869/modares.iem.2.4.32

Boukary AR, Saegerman C, Abatih E, Fretin D, Bada R A, De Deken R, Harouna H A, Yenikoye A and Thys E (2013). Seroprevalence and potential risk factors for Brucella Spp. infection in traditional cattle, sheep and goats reared in urban, periurban and rural areas of Niger. PLoS One 8: 112. DOI: https://www.doi.org/10.1371/journal.pone.0083175

Corbel MJ (2006). Brucellosis in Humans and Animals, WHO/FAO/WOAH, Available https://www.who.int/csr/resources/publications/Brucellosis.pdf?ua=1

Diaz R, Garatea P, Jones LM and Moriyon I (1979). Radial immunodiffusion test with a Brucella polysaccharide antigen for differentiating infected from vaccinated cattle. Journal of Clinical Microbiology, 10: 37-41. Available at: https://www.ncbi.nlm.nih.gov/pmc/articles/PMC273089/

Diaz R, Toyos J, Salvo MD, Fernandez-Lago L, Alonso B, Moriyon I and Dorronsoro I (1983). 3rd International Symposium on Brucellosis, Algiers, 
Algeria, 1983. In: Studies on the Polysaccharide B and Native Haptene of Brucella and Yersinia Enterocolitica Serotype 9, Available at: https://pubmed.ncbi.nlm.nih.gov/6436095/

Díaz R, Toyos J, Salvo M D, Fernández-Lago L, Alonso-Urmeneta B, Moriyón I and Dorronsoro I (1984). Studies on the polysaccharide B and native haptene of Brucella and Yersinia enterocolitica serotype 9. Developments in biological standardization, 56: 213-220. Available at: https://pubmed.ncbi.nlm.nih.gov/6436095/

Diaz R, Toyos J, Salvó MD and Pardo ML (1981). A simple method for the extraction of polysaccharide B from Brucella cells for use in the radial immunodiffusion test diagnosis of bovine brucellosis. Annals Research Veterinary, 12: 35-39. Available at: https://pubmed.ncbi.nlm.nih.gov/6805406/

Diaz-Aparicio E, Aragon V, Marin C, Alonso B, Font M, Moreno E, Perez- Ortiz S, Blasco J M, Diaz R and Moriyon I (1993). Comparative analysis of Brucella serotype A and $\mathrm{M}$ and Yersinia enterocolitica O:9 polysaccharides for serological diagnosis of brucellosis in cattle, sheep, and goats. Journal of Clinical Microbiology, 31: 3136-3141. Available at: https://www.ncbi.nlm.nih.gov/pmc/articles/PMC266364/

Diaz-Aparicio E, Marin C, Alonso-Urmeneta B, Aragon V, Perez-Ortiz S, Pardo M, Blasco J M, Diaz R and Moriyon I (1994). Evaluation of serological tests for diagnosis of Brucella melitensis infection of goats. Journal of Clinical Microbiology, 32: 1159-1165. Available at: https://jcm.asm.org/content/32/5/1159

Ducrotoy M, Bertu WJ, Matope G, Cadmus S, Conde-Álvarez R, Gusi M, Welburn S, Ocholi R, Blasco JM and Moriyón (2015). Brucellosis in SubSaharan Africa: Current challenges for management, diagnosis and control. Acta Tropica, 1-15. DOI: https://www.doi.org/10.1016/j.actatropica.2015.10.023

Ducrotoy MJ, Conde-Álvarez R, Blasco JM and Moriyón I (2016). A review of the basis of the immunological diagnosis of ruminant. Veterinary Immunology and Immunopathology, 171: 81-102. DOI: https://www.doi.org/10.1016/j.vetimm.2016.02.002

Ducrotoy MJ, Pilar M Muñoz, Raquel Conde-Álvarez,José M Blasco and Ignacio Moriyón (2018). A systematic review of current immunological tests for the diagnosis of cattle brucellosis. Preventive Veterinary Medicine, 151: 57-72. DOI: https://www.doi.org/10.1016/j.prevetmed.2018.01.005

Grace D, Mutua F, Ochungo P, Kruska R, Jones K, Brierley L, Lapar L, Said M, Herrero M, Pham DP et al. (2012). Mapping of poverty and likely zoonoses hotspots 1-119. Available at: http://hdl.handle.net/10568/21161

Hamdi-Chérif M, Hamouda RA, Touabti A, Sedjal R, Kharchi R, Zellagui A, Kaouane R, Laala A, Lecheheb A, Mahnane A and Laouamri S (1999). La brucellose dans les hauts plateaux setifiens et les hautes steppes de M'sila, Relevé épidemiologique mensuel, Available at: http://www.insp.dz/index.php/Non-categorise/rapports-periodiques.html

Hull NC and Schumaker BA (2018). Comparisons of brucellosis between human and veterinary medicine. Infection Ecology and Epidemiology, 8: 1500846. DOI: https://www.doi.org/10.1080/20008686.2018.1500846

Robert H (2016). Brucellosis outbreak in Algeria exceeds 800 people year to date, Available at: http://outbreaknewstoday.com/

Jones BA, Grace D, Kock R, Alonso S, Rushton J, Said MY, McKeever D, Mutua F, Young J, McDermott J and Pfeiffer DU (2013). Zoonosis emergence linked to agricultural intensification and environmental change. Proceedings of the National Academy of Sciences, U.S.A., 110: 8399-8404. DOI: http://www.doi.org/10.1073/pnas.1208059110

Jones LM, Berman DT, Moreno E, Deyoe B L, Gilsdorf MJ, Huber JD and Nicoletti P (1980). Evaluation of a radial immunodiffusion test with polysaccharide B antigen for diagnosis of bovine brucellosis. Journal of Clinical Microbiology, 12: 753-760. Available at: https://jcm.asm.org/content/12/6/753

Kebede T, Ejeta G and Ameni G (2008). Seroprevalence of bovine brucellosis in smallholder farms in central Ethiopia (Wuchale-Jida district). Revue de Médecine Vétérinaire. (Toulouse), 159: 3-9. Available at: https://www.revmedvet.com/artdes-us.php?id=1584

McDermott J, Grace D and Zinsstag J (2013). Economics of brucellosis impact and control in low-income countries. Revue scientifique et technique. Office international des épizooties, 32: 249-261. DOI: http://www.doi.org/10.20506/rst.32.1.2197

McGiven JA (2013). New developments in the immunodiagnosis of brucellosis in livestock and wildlife. Revue scientifique et technique. Office international des épizooties, 32: 163-176. DOI: http://www.doi.org/10.20506/rst.32.1.2205

Meskoud-taibi M and Benzadi O (2009). Méthodologie de prélèvement Bilan du programme de dépistage des maladies contagieuses, Available at: https://www.univ-blida.dz/

Mohammed FU, Ibrahim S, Ajogi I and Olaniyi BJO (2011). Prevalence of Bovine Brucellosis and Risk Factors Assessment in Cattle Herds in Jigawa State. ISRN Veterinary Science, 2011: 1-4. DOI: https://www.doi.org/10.5402/2011/132897

Muñoz PM, Marín CM, Monreal D, González D, Garin-Bastuji B, Díaz R, Mainar-Jaime RC, Moriyón I and Blasco JM (2005). Efficacy of several serological tests and antigens for diagnosis of bovine brucellosis in the presence of false-positive serological results due to Yersinia enterocolitica O:9. Clin. Diagn. Lab. Immunol, 12: 141-151. DOI: http://www.doi.org/10.1128/CDLI.12.1.141-151.2005

Nielsen K and Duncan JR (1990). Animal Brucellosis. Nepean, Ontario. Available at: https://www.routledge.com/AnimalBrucellosis/Nielsen/p/book/9781315890586

Nielsen KH (2002). Diagnosis of brucellosis by serology. Vet. Microbiol, 90: 447-459. DOI: http://www.doi.org/10.1016/s0378-1135(02)00229-8

O'Callaghan D (2020). Human brucellosis: recent advances and future challenge. In: Infectious Diseases of Poverty, 9: 101. DOI: https://www.doi.org/10.1186/s40249-020-00715-1

OIE (2016). Brucellosis (Brucella abortus, B. Melitensis and B. Suis). In: Manual of Diagnostic Tests and Vaccines for Terrestrial Animals, Available at: https://www.oie.int/standard-setting/terrestrial-manual/

Olabode HOK, Adah B, Nafarnda WD, Aworh MKF and Bello RH(2012). Sero-prevalence of brucella abortus antibodies in slaughtered cattle and meat by-product handlers in Ilorin abattior , Kwara state - Nigeria. Prime. Journal of Microbiology Research, 2: 109-113. Available at: http://www.primejournal.org/PJMR/

ONS (2008). Recensement général de la population et de l'habitat. Alger, Availbale at: http://www.ons.dz/spip.php?rubrique33

Rahman MS, Faruk MO, Her M, Kim JY, Kang SI and Jung SC (2011). Prevalence of brucellosis in ruminants in Bangladesh. Vet. Med. (Praha), 56: 379-385. DOI: http://www.doi.org/10.17221/1555-VETMED

Toma B, Dufour B, Sanaa M, Bénet JJ, Ellis P, Moutou F and Louzä A (1996). Epidémiologie appliquée à la lutte collective contre les maladies animales transmissibles majeures, Médecine et Maladies Infectieuses, Available at: https://www.oie.int/fr/

Verger JM, Garin-Bastuji B, Grayon M and Mahé AM (1989). La brucellose bovine à Brucella melitensis en France.Annales de Recherches Vétérinaires, INRA Editions, 20 (1): 93-102. hal-00901847. Available at: https://hal.archives-ouvertes.fr/ARINRA-ARV 